\title{
Et Pilate s'est lavé les mains : rhapsodie en cinq actes
}

\section{Sante Viselli}

\section{I}

Un peu de solitude rapproche les gens

Et le silence souvent d'or invite à méditer

Mais le Christ livré à son fardeau inédit,

Paradoxal, invraisemblable,

En chemin vers l'hôpital, lieu chagrin de tant de souffrance,

Prie tout seul, la couronne d'aiguilles enfoncée dans la poitrine,

Le sang ruisselant du côté droit de son corps, légèrement penché sur son côté,

Un sourire acquiesçant sur ses lèvres gercées

Pour répandre l'amertume d'une douce pensée avant de crier adieu au monde.

Et le Cœur, ce doux ami de tant d'émotions, bat la retraite des domptés,

Accablés par le Virus,

Couronne d'opprobres, Mal de tous.

Et Ponce Pilate se lave les mains pour échapper au jugement du vulgus.

Le malheur de l'homme, c'est de ne pas savoir rester seul dans une chambre

Pascal le pensait en regardant la multitude divertie, abasourdie par ses cris sombres, menaçants,

Les Romains dans leur Colisée, les Français à la Cour, les Américains dans les rues, dans les villes infectées, criant leur droit à la liberté, les Canadiens dansant autour d'un feu, bien blottis devant la cheminée, sur les Rocheuses immaculées ou les côtes de l'Atlantique,

Tous les peuples de la Terre cherchant une frontière à leur vie injuste,

Une distance physique de deux mètres et l'horreur des mains sales aseptisées à l'eau de javel,

La raison de leur ennui dans la nuit existentielle de l'absurde réalité entropique.

La pandémie bloque l'univers, mais l'égoïsme, l'orgueil, l'ignorance et même le fanatisme

Continuent à souffler sur les mers inexplorées du mystère onirique qui menace

l'existence,

Entre la vie et la mort, Amour,

Tout seul, pourras-tu encore sauver l'être de la démence?

Et P.P. demande le bassin de l'absolution. 


\section{II}

Dans ma bibliothèque, mes chers amis couverts de sagesse et de poussière, Je vous revois enfin en compagnie de mes plumes coupées, prêtes à s'envoler sur les feuilles nues de mes rêves jaunis des regrets.

Leopardi et l'infini, ta marâtre Nature princesse des opprobres, Qui trompe l'être dès que la lumière le blesse, Rabelais et ton rire thérapeutique, prière des mélancoliques, ivresse d'un requiem, Socrate, Platon, Aristote et Homère, le divin aveugle clairvoyant et sublime, La Bible et tes symboles, tu illumines la route vers l'oubli du monde, Et Babel l'inonde de frénésie et d'ignorance,

Livres oubliés dans la nuit de ma jeunesse heureuse, insouciante, riche de croyances, Baudelaire, tes correspondances et ta Nature matrice, boussole caressante,

Catalyseur analeptique, Temple jamais remplacé par une autre Puissance, Chronotope incompréhensible au milieu de la foule capitaliste, Capital de l'esprit délapidé par le Cannibalisme de la Bourse Dans la course effrénée vers la source d'un bonheur opaque, délirant, Cloaque pensant, toujours instable, sans foi, sans Repos ni Espérance

L'Argent, agent d'une ravissante chimère dans les caves de l'insouciance.

Dante et tes gironi mélancoliques et amers,

Avant d'atteindre les deux Soleils, l'éther limpide du non-être, Avant de comprendre l'Amour, au-delà de l'Enfer.

Je vous retrouve, chers amis d'un temps meilleur,

Dans ma chambre fermée doublement à clé pour échapper aux cris des vivants, Des doms juan qui passent dans la rue en chantant,

Qui accusent les Monstres du passé, l'inquisition, les préjugés, le fanatisme,

Des lois sans esprit, des mœurs sans référents,

Montesquieu et tes lieux peu communs, despote toi aussi de l'irrationnel et de la dive

Raison,

Voltaire et tes moutons

Ils pourront enfin te résoudre à surmonter les obstacles de la Dive Bourse, génie du Mal aux lisières d'autres cataclysmes, d'autres marchés, d'autres virus,

Rousseau dans un coin bien caché, sirotant un dernier soupçon de pinard,

Tu cogites tout seul en te promenant sur les écueils du Contrat et la cécité des hommes,

Molière ami des misanthropes, des écoles des maris et des femmes trompés et infidèles, Virgile et Sénèque, Corneille et Shakespeare, Cervantès, Camus, Pétrarque, Boccace, Le Tasse, et j'en passe,

La Mort n'a jamais bercé votre vieillesse malgré la peste, la guerre et les tremblements de terre,

Tous Solitaires

Tous Solidaires 
Mes Livres, chers amis d'un temps meilleur et de mon heureuse solitude, Je vous ai tous autour de moi, sur les rayons couverts de poussière et mes trophées de coureur solitaire,

Suivant les sentiers écartés, ceux qui ne me ramènent plus à Rome.

Je souffle sur le détritus pour retrouver l'esprit derrière la lettre, la pensée qui masque le

Beau.

Même en courant autour de ma chambre, j'aurai retrouvé le temps de tout faire, À un âge où la sagesse me délaisse, sans ennui ni défi, écarté de la foultitude, «Je ne serai jamais seul avec ma solitude».

P.P. refuse de se laver les mains.

La pandémie du coup acquiert une autre dimension - démentielle certes - spirituelle virtuelle, existentielle au-delà de la peur, Mystérieuse, au-delà de la rage de vaincre l'ennemi sans visage :

La victoire sur l'égoïsme s'appelle

Cœur, altruisme, Courage et Miséricorde, Espérance, Gare à la Violence, à l'Angoisse, Place au Pardon, à la Foi, à la Paix, À la Générosité dans le Désert et les tourments,

Générosité sans frontières,

Mais hélas ! elle ne touche que les aveugles miraculés, Souvent elle a les poches vides et le cœur gros, L'âme s'apitoie, une larme furtive s'échappe des yeux impuissants, Incapables de défier le Monstre, la raison coupable de trahison.

P.P. doit-il se laver les mains ?

III

Aujourd'hui 10 avril 2020 le Christ est de nouveau mort, Crucifié tout seul - même les larrons l'ont abandonné, Ils seraient trop près de lui et la loi l'interdit, Il faudra envisager le calvaire en héros, sans couronne, sans compagnons, Sans la consolation de ces femmes qui chantent le requiem tout bas, Un écran les sépare de la croix.

Tout seul il affronte depuis deux mille ans la torpeur accablante de la nuit, Tout seul dans les églises, est monté à coup de fouet sur tous les Golgotha du monde Et regarde d'un œil hagard la Place St-Pierre vide et toutes les cathédrales en feu, Sa parole urbi et orbi se masque derrière les nuages virtuels de la science, Jamais on n'a vu tant de nuages sur le front courroucé des humains, Tant écouté le silence du sépulcre de toutes les latitudes. 
Une voix chétive - un enfant avant de s'endormir, un soldat avant l'assaut, un amant qui réclame la dernière grâce à la dame sans merci, un petit chien devant un biscuit, un numéro exhalant son dernier soupir dans l'anonymat et le mutisme d'une maison de retraite - Une voix pathétique implore :

-Deus absconditus reviens consoler les malheureux qui refusent de s'apaiser!

J'aurais tant envie de revoir encore une fois le printemps, mes enfants et mes amis, Sentir de nouveau l'haleine syncopé de mon chien, le chant du chœur le Dimanche de Pâques, Surprendre mon jardin grouiller, les tomates et le basilique en herbe vibrant de vie et d'espoir, Le soleil et la longue lumière aux portes du renouveau

- et Moi, chétif, ne puis que réciter la prière des morts !

Je sens la fraîcheur de cette main amicale protégée par un gant, elle me verse son obole bienfaisante, Attentive et ne me prive pas d'un dernier sourire fatigué, M'accompagne doucement vers la barque fatale de l'autre rive.

Je n'ai plus peur, ses mains sont propres, elle se les est souvent lavées.

\section{IV}

Dimanche, lointain et muet, le Christ ressuscitera tout seul et sur la Terre, le désert remplacera la voie du désespoir, La communauté des morts-vivants souffrira dans les maisons de retraite Et le drogué attendra sa dernière cène sur le trottoir en tournant les yeux vers le Ciel. La Coupe est vide et les champs stériles, l'Eau trop froide, trop gelée pour se laver les mains, L’Homme méprisant, l’Homme débile

Virus - venin - vir - mâle - homme - il s'appelle Légion dans l'Évangile.

Toutes les nations du monde se lavent les mains et gardent leur distance, La première loi de la nature est la survivance.

Ponce Pilate s'est lavé les mains jadis,

Il ne savait quoi faire devant le Malheur, la fatalité du Mal,

Dante a traversé l'Enfer,

Don Quichotte s'est battu contre les moulins à vent, Voltaire conte l'Infâme, Éluard a érigé la liberté en déesse, Mais la vérité est invisible aux pauvres d'esprits, ils sentent et ne raisonnent pas, Le masque a fermé à jamais les bouches hébétées, Le bouclier les yeux assoiffés de dévoiler l'énigme de l'existence. 


\section{V}

La couronne d'épines l'a emporté sur notre insuffisance, sur la Bourse et la Charité.

Nous regrettons :

Les écoles fermées,

Les bureaux fermés,

Les restaurants fermés,

Les jardins publics fermés,

Les églises, les temples, les synagogues et les cimetières

Accompagnent les morts sans prières,

La gorge et le Cœur fermés, les sanglots étouffés par un brin inutile de fierté

amère.

Dans ce paradis des psychiatres, hôpital de héros et de détresse,

La solitude me ramène vers vous, mes amis les livres,

Confiné, je puis jouir du calme du sage, du Temps qui passe sans traumatismes,

De l'humanité captive en chemin vers les espaces rêvés du Beau,

Du bonheur d'écouter en silence la Nature, un simple oiseau qui vole près de la fenêtre,

D'être touché outre mesure du virus de l'Amour.

Dimanche, jour de Pâques, on n'entend pas les cento campane de Rome, un jour saint mais sans ces violettes cueillies fraîches par les doigts d'un enfant amoureux du printemps et des sortilèges en couleur sur les bords de ce ruisseau disparu lui aussi près de sa vieille maison. Un sourire virtuel vous est parvenu des villes en béton, serein, sans nuages, froid certes, un peu figé comme les milliers de cadavres qui attendent dans les morgues, un numéro affiché sur leur corps, en paix dans leur scandaleuse solitude, un linceul couvrant les signes de la dernière douleur et du deuil.

Le Virus, l'Amour et la Musique,

Triumvirus de la nouvelle démocratie, de la Mort et de la pitié,

Sont à présent le seul langage compris par tout l'univers :

Est-ce le Mal ou le Bien qui rassemble les peuples de la Terre?

P. P. continue à se laver les mains, elles sont tellement lessivées qu'on ne peut plus les joindre.

Un coup d'Amarone autour de la table déserte éloigne les mauvais esprits et leurs hallucinations,

Je pense à mes enfants, à la distance qui me sépare de leur jeune rire cristallin, de leur cœur en couleurs, À ma famille, à tous ces amis dispersés aux quatre coins du monde, Aux victimes assassinées de toutes les latitudes, Aux indifférents, aux cyniques, À ceux qui pri(r)ent, à ceux qui donnent,

Une pensée s'envole vers ceux qui souffrent, qui revivent la croix des opprobres. 
Je prends mon ordi portatif, deux anges de leur voix douce me demandent : comment vastu nonno ? Tu viendras nous voir à Noël ? Il fait toujours beau chez nous.

Le Soleil décide de quitter la tristesse et ses ombres, Aurore se lève déjà pour reprendre sa course. 